\title{
The nexus between OSH and subcontracting
}

\author{
Isabel L. Nunes* \\ Departamento Engenharia Mecânica e Industrial, Faculdade de Ciências e Tecnologia / Universidade Nova de \\ Lisboa, Campus de Caparica, 2829-516 Caparica, Portugal \\ Centro de Tecnologia e Sistemas, UNINOVA, Campus de Caparica, 2829-516 Caparica, Portugal
}

\begin{abstract}
Subcontracting of specialized functions to external companies (e.g. cleaning or maintenance) is actually very common within several industries. These external companies' are called contractors and their contracting is often designated as outsourcing. Frequently contractors involve other companies (the sub-contractors) to assist them in fulfilling the contract, resulting in a complex chain of organizations focused on interchange of work - the contracting chain. Therefore in the same work site can coexist workers form the client-company and workers from the contractors and/or subcontractors. Since contractors perform their job in client's facilities, they can be exposed to hazards that are unknown to them. On other hand, workers of the client company can also be exposed to hazardous situations derived from the work performed by the contractors. The paper discusses how adequate occupational safety and health conditions can be assured when dealing with this kind of dynamic labor networks. Two case-studies and several examples coming from international literature will be presented.
\end{abstract}

Keywords: Supply Chain, Outsourcing, Contractor workers, Occupational Safety and Health

*Corresponding author. E-mail: imn@fct.unl.pt. 


\section{Introduction}

Subcontracting of specialized functions to external companies (e.g. cleaning or maintenance) is actually very common within several industries, such as construction, chemical, transport, or energy. These external companies' are called contractors and their contracting is often designated as outsourcing. Contractors usually are small or medium size companies or even an individual worker that works for a company but is not an employee of that company. Typically they are engaged because they perform the work better, faster and usually cheaper [16].

Outsourcing is related with a reduction of employment in large companies, a growth of employment in small and medium-sized enterprises, and a significant rise in 'non-permanent' labor, particularly in the form of self-employment and temporary work [14].

Frequently contractors involve other companies (the sub-contractors) to assist them in fulfilling the contract, resulting in a complex chain of organizations focused on interchange of work, which leads to complex forms of communication. The type of chains of suppliers and (sub-)contractors which are formedthe contracting chain, is presented in Figure 1, where:

- Client - is the public or private company that outsources the work, being the work usually performed at the client facility;

- Contractor - is the company that signs the contract with the client for providing goods or services and who is not an employee of the client;

- Sub-contractor - is a third company contracted by the contractor, for example for specialized works or to help accomplish the contracted work.

The fact that contractors frequently perform their work in client's facilities can exposed them to unknown Occupational Safety and Health (OSH) hazards, such as noise, vibration, microbiological agents, chemical substances or unprotected machine parts. Conversely, the workers of the client company can also be exposed to hazardous situations derived from the work performed by contractors. These situations are mainly originated by activities not familiar to the company workers or by activities that are performed suddenly [2]. Potential hazardous situations must be identified and controlled before scheduling and executing the contracted tasks. Therefore, promoting and ensuring workers safety and health in this complex chain of organizations is vital.

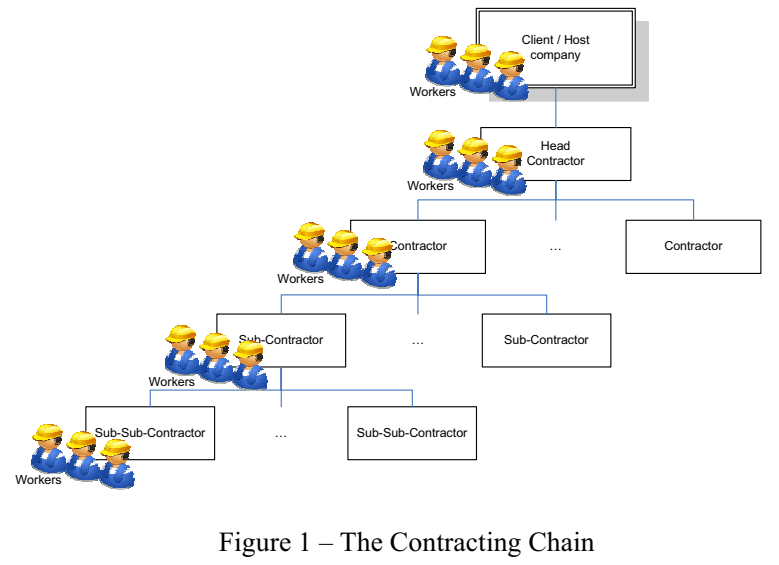

The paper discusses how adequate occupational safety and health conditions can be assured when dealing with this kind of dynamic labor networks.

A summary of two case-studies and several examples coming from international literature will be presented. These examples include good practices found in companies, such as OSH guidelines made available to all workers (employees and contract workers); Work permits; Safety passports; Advice, audits and training of contractors and information and training of workers.

\section{OSH in outsourcing}

Outsourcing offers the possibility to shift activities to more specialized companies and to transfer work to an environment in which relevant work-related risks are better understood and better controlled ([9]; [14]). For instance, in European Union it is mandatory to contract a certified specialized company which has the necessary expertise, to perform the highly hazardous activities involved in asbestos removal.

However, as some authors point (e.g., [13]; [14]; [16]) outsourcing also create vulnerabilities that may have impact in the OSH of contractors, such as:

- fragmented employment relationships - for instance, due to diffuse or unclear management control and responsibilities;

- cultural and linguistic barriers - in a globalized economy, where national barriers almost disappeared, workforce mobility and diversity leads to a mix of cultures and languages; 
- supervision and training of sub-contracted workers - may be lower than for clients' workers;

- long and complex communication lines - this can lead to poor levels of communication between client managers and sub-contracted workers;

- high work intensity of sub-contracted workers due to peaks in workload, multitasking, increased work periods and unpaid overtime;

- decline of the full-time workforce - increased proportion of part-time work (temporary, fixedterm or leased), growing use of (multi-tiered) sub-contracted workers.

Besides these vulnerabilities, other issues can affect the OSH performance of contractors related, for instance, with the fact that the contracted companies tend to be small organizations, lacking a skilled and experienced workforce. The low profile of these small enterprises, which probably possess less adequate and sophisticated systems of risk management and the low frequency with which they are inspected, together with the competition associated with commercial contracts can limit the ability of those contractors to invest in preventive health and safety measures. Job insecurity, illegal employment, poor payment, low access to training and low control over working time by workers, combined with a limited access of workers to trade unions and other forms of collective organizations that can promote better health and safety and more adequate risk management systems, contribute also to a lack of knowledge and awareness regarding safety issues and complaints among (sub-) contracted workers [14].

Contracted jobs can be particularly risky because they are done on host company premises, usually in situations which are unfamiliar to (sub-)contractors' workers where they may be exposed to unknown hazards, and also because host companies' employees may not be aware that (sub-)contractors are working nearby ([6]; [14]).

Walters and James [14] refer that injury rates vary negatively with both workplace and establishment size, this way a shift of work activities to smaller workplaces and organizations is likely to be associated with a rise in their 'riskiness'.

Literature reveals many examples of injuries or disasters in different occupational sectors resulting from inadequate management and control of (sub-) contracted workforce and their interaction with clients' employees, which lead to an increase in the accident rate for contract workers because overall safety management control and responsibilities are more diffused in these situations. For instance, French National Assembly's investigation regarding an explosion that occurred in Toulouse, in September 2001, at the AZF chemical factory and where 30 people were killed (13 were subcontractors' workers), determined that a critical factor was problems with contractor's safety management [10].

The root causes for most OSH incidents are related with:

- Misunderstanding and insufficient information sharing;

- Conflicting goals (lack of common understanding and agreement on what has to be done);

- Lack of common methods and procedures (lack of common understanding and agreement on how is going to be done);

- Unclear responsibilities for control and coordination (role ambiguity) (lack of common understanding and agreement on who is in charge and what are the different responsibilities);

- Ineffective planning and implementation of safety measures;

- Insufficient workforce training;

- Inadequate (sub-)contractors selection;

- Loss of corporate memory of health and safety issues (poor safety records).

According to Habilis Ltd, 2004 and Zwetsloot et al. 2007 (cited in [16]), the large number and the diversity of stakeholders involved appear to have negative consequences on attention paid to safety.

Construction sector is the one where outsourcing is used more frequently. As cited in [16], regarding occupational safety in construction projects: 
- tasks delegated to (sub-)contractors are typically high risk, and in many cases, contractors do the hard physical and dirty labor in relatively bad labor circumstances;

- workload of (sub-)contractors is generally high since they have to achieve high quality results in a limited amount of time for a limited amount of money.

Regarding health problems an increased incidence of cardiovascular disease, burnout and depression is referred by (Kivimaki et al., cited in [14]).

Considering these indirect effects of outsourcing, promoting and ensuring workers safety and health in this complex chain of organizations is of utmost importance.

\section{Legal requirements}

In Europe, OSH regulation regarding working with contractors is not clearly regulated. Some implications can though be derived from the Framework Directive (Council Directive 89/391/EEC, of 12 June 1989) [5]. For instance, clients have to provide contractors appropriate instructions regarding safety and health risks during their activities and regarding the corresponding safety measures. Also client and contractor should cooperate in order to avoid exposing their workers to hazardous situations. To accomplish such objective both employers (client and contractor) shall inform one another and their respective workers and/ or workers' representatives about the potential hazardous situations they can face. They shall also coordinate their actions in matters of protection and prevention of occupational risks.

Having in mind this legal requirement in Europe and taking into account the relationship that is established between client and (sub)-contractor it is advisable that risk assessments are conducted jointly by these entities [1], [2], [7].

Individual Directives on the implementation of minimum OSH requirements, addressing different types of risk exposures have being issued to complement the Framework Directive. For instance, in construction, the Council Directive 92/57/EEC of 24 June 1992 that addresses the minimum OSH requirements at temporary or mobile construction sites (any construction site at which building or civil engineering works are carried out, which include repair and maintenance activities), establishes that the client or the project supervisor shall appoint one or more coordinators for $\mathrm{OSH}$ matters for any construction site on which more than one contractor is present.

In U.S., federal Occupational Safety and Health Act of 1970 (OSH Act) establishes the "Right to Know", stating that workers have to be informed about the hazards they are exposed to, the harm they might cause, and precautions that could prevent these harmful effects. This should also comprise contracted workers.

Despite these obligations and recommendations many negative consequences of outsourcing persist affecting the health and safety of workers, which are discussed in literature, together with approaches to counter them. Some of the main approaches developed to promote $\mathrm{OSH}$ in the contracting chain are presented in next section.

\section{Approaches to promote OSH in outsourcing}

Several approaches, good practices, instruments or strategies have been implemented by companies to control risks and promote OSH throughout this complex organizational form that is the contracting chain.

The first very important and crucial approach is the involvement of clients and (sub-)contractors in all phases of the interaction between them. It should begin at the pre-contract stage with a thorough assessment of (sub-)contractor competence; continues throughout the job execution via close cooperation of all parties and appropriate levels of supervision; and, at contract termination, ends by reviewing and recording the $\mathrm{OSH}$ performance of contractors and subcontractors.

From a literature review it was possible to identify several efforts to influence OSH within contractor chains that can contribute to high OSH performance. Some of these approaches are summarized below.

Selecting "safe (sub-)contractors" - where OSH requirements are used as a basis for the selection of skilled, competent and knowledgeable contractors [7], [11]; [15]; [16].

OSH Certification Schemes - the adoption of certification schemes helps to ensure the competencies of contractors and contributes to improve the OSH standards [15]. OSH certification schemes can be as- 
signed to workers or companies. An example of an individual certification scheme is the Safety Passport (SP). SP is a card that allows controlling the access to work sites, ensuring that only workers with a basic OSH awareness training are allowed to work. Therefore, SP helps promoting good practices and reducing occupational accidents and disorders. This system is especially useful for workers and contractors who work in more than one facility of a company. SP is a progressively important system for companies who hire contractors, to establish OSH competence among their workforce [8]. An example of a safety contractor certification scheme is the VCA. VCA is the Dutch acronym for Safety, Health and Environment Checklist for Contractors. VCA was developed by the Dutch petrochemical industry in the 1990s and is the most well know European safety certification scheme. VCA uses a checklist (extensive questionnaire) to investigate contractors' critical points for $\mathrm{OSH}$ and environmentally-friendly working practices. If the contractor meets the required standards, a VCA certificate may be obtained. VCA is intended to contractors that perform in high-risk working environments such as construction, maintenance and industrial cleaning [12]. More information about certification schemes can be found in [17].

Imposition of requirements - this approach relates to the general management of $\mathrm{OSH}$, and includes carrying out risk assessments and communication within multi-contractor work sites [15].

Planning - a careful planning of contracted work allows for a timely definition of $\mathrm{OSH}$ requirements considering potential hazards, measures to eliminate or limit them, precautions that still need to be taken, and a description of safe behaviors ( [11], [16]).

Cooperation - cooperation between client and (sub-)contractors improves sharing knowledge, awareness and understanding of activities, responsibilities and risks. The client should inform their workers about the presence of (sub-) contractors and the tasks they are performing. The client should inform the (sub-)contractor workers about their own safety procedures, risks related to the tasks and preventive measures ([5], [6], [11], [15],[16]).

Permit-To-Work System - is a formal written system used to control potentially hazardous jobs, for instance, entry into vessels, hot work and pipeline breaking. Permits-to-work form an essential part of safe systems of work for many maintenance activities, particularly in the chemical industry.

Reduction of organizational complexity -dividing a project in smaller projects, combined with a risk assessment for each small project, contributes to improve OSH performance (Frijters, 2005, cited in [16]).

Responsibilities clarification - clear definition of responsibilities from the early stages of the contract contributes to improve OSH. In fact this is also necessary, since both parties have legal obligations under health and safety laws ([7]; [11]).

Long term relationships - a lasting cooperation helps creating a joint OSH and cooperation culture (Riedijk, 2001, cited in [16]).

Leadership - an active leadership at all levels regarding OSH matters improves safety and health performance [16].

Training and Education - training and education on $\mathrm{OSH}$ issues aligns standards and procedures among client and contractors, harmonizes safety culture and improves OSH performance ([6]; [7]; [16]).

Joint safety management systems - common standards and procedures among client and contractors improves OSH performance (Riedijk, 2001 and Goudswaard, 2002, cited in [16]); ([5], [6], [7]).

Safety inspections - implementation and recording of control procedures (e.g. investigation of all injuries, near misses and occupational disorders) contributes to improving OSH performance (Amerongen, 2007, cited in [16]).

Company internal policy - companies that want to have good image in the market, start to show a commitment to protect OSH of their workers and the contractor workers. For instance, in Portugal, a large company that wanted to be quoted on stock market implemented an OSH management system, which included several initiatives to protect contract workers.

Some other examples of good practices applied to specific sectors can be found in literature, for instance in [3] (for the cleaning sector) and [4] (for the maintenance sector).

\section{Summary of two case studies}

A brief summary of two case studies related with contracting chain is presented. These case studies are illustrative of two different approaches, both aiming at ensuring an adequate level of OSH awareness and practice by contractors. The first one regards the certification of contractor workers to operate inside the facilities of the client company. The second regards $\mathrm{OSH}$ requirements set by the client that contractors must fulfill to become eligible to supply goods or services. 


\subsection{Safety, Health and Environment Card}

A multinational enterprise with several industrial sites in Portugal has prepared and implemented a Safety, Health and Environment Card (SHE Card) with the objective of ensuring that all contractors working on those sites are "certified" concerning SHE matters. The access of contractor workers to facilities is controlled based on this passport. One worker "certified" by one site is automatically "certified" to the other company sites thus avoiding repetition of training.

Usually contractors are small companies with few workers, some of them immigrants. The aim of issuing the SHE card is that all workers of the hired contractor (regardless of skill level, school degree, professional category or function) acquire an acceptable level of $\mathrm{OSH}$ and environmental knowledge, improving their safety culture and being able to work safely in any undertaking of the Company. To receive the SHE Card contractor workers attend induction sessions relevant to the work they will perform. At the end of the each session an evaluation test is applied in order to obtain initial feedback on the success of the training.

Apart from being an internal requirement the implementation of SHE Card also contributes to the fulfillment of the company's legal obligations in terms of OSH training.

The main challenges with the implementation of the SHE Card were: (1) high rotation of contractor workers; (2) difficulties in planning the induction/training sessions, due to short duration of some contracted tasks; and (3) poor language skills by immigrant workers.

The main outcome of SHE Card implementation is an increase of workers awareness on OSH and environmental matters. One key success factor is related with the tailoring of the program to the tasks performed by workers.

\subsection{Obligation to implement an OSH management system}

A multinational company from the food sector with many retail shops in Portugal has a contracting policy that sets the obligation for the contractors to implement an OSH management system. Some of the required steps are performing a thorough risk analysis (to facilities, equipment, processes and environment) and implementing measures to improve $\mathrm{OSH}$ and working conditions for workers. In a specific case, as a result of the risk analysis, a contractor concluded that one of the major issues was related with the thermal work environment, which was very stressful for the worker. In this case measures to insulate the roof and the installation of ventilation were taken.

This policy contributes to the implementation of $\mathrm{OSH}$ management systems in small contractor companies, raising awareness on OSH matters, minimizing incidents, preventing accidents and contributing for better working conditions. This type of initiatives is propagating to other large clients (mainly multinational companies) which are applying the same type of policies to their contractors.

\section{Conclusions}

Outsourcing specialized functions to external companies is nowadays very common. According to literature and to practical knowledge this is associated with an increased exposure of workers (contractor's and clients) to potential hazardous situations.

The current paper presents and briefly discusses OSH in outsourcing and presents several approaches, good practices, instruments or strategies, which are oriented at providing adequate $\mathrm{OSH}$ conditions in contracting chain.

Some of the approaches that help the promotion of OSH include, for instance: effective communication structure; sharing knowledge and ensuring that risks are identified and eliminated or controlled; including information in contracts on the potential hazards, measures that have been taken to eliminate or limit them, precautions that still need to be taken, and recommendation of safe behaviors; clients informing their workers about the presence of contractors and the tasks they are performing; and clients informing contractor workers about their own safety procedures, as well as any risks related to the task and preventive measures that have been taken.

Thus, prevention of risks during outsourced activities should result from a combined effort of all parties involved: clients, (sub-)contractors and workers.

Two case studies were presented illustrating different instruments to ensure or improve OSH on contractors. One case study (SHE Card) affects contrac- 
tor workers working on clients facilities, while the second (OSH management system) is focused on ensuring adequate $\mathrm{OSH}$ conditions in contractors facilities. Both approaches contribute to minimizing incidents and preventing accidents.

ACKNOWLEDGMENTS: This work was funded by the Portuguese Foundation for Science and Technology, project number MIT-Pt/EDAM-IASC/0033/2008.

\section{References}

[1] D.E. Cantor, Workplace safety in the supply chain: a review of the literature and call for research. The International Journal of Logistics Management 2008. 19(1): p. 65-83.

[2] EU-OSHA, Guidance on Risk Assessment at Work. Available at: http://osha.europa.eu/en/topics/riskassessment/ guidance.pdf 1996, European Agency for Safety and Health at Work.

[3] EU-OSHA, Preventing harm to cleaning workers. Available at: $\quad$ http://osha.europa.eu/en/publications/reports/ TEWE09006ENC. 2009, European Agency for Safety and Health at Work.

[4] EU-OSHA, Safe maintenance in practice. Available at: http://osha.europa.eu/en/publications/reports/safemaintenance-TEWE10003ENC. 2010, European Agency for Safety and Health at Work

[5] EU, Directive 89/391/EEC of 12 June 1989 on the introduction of measures to encourage improvements in the safety and health of workers at work (Framework Directive). Official Journal L 183 , 29/06/1989 P. 0001 - 0008, 1989. http://eur-lex.europa.eu/LexUriServ/LexUriServ.do?uri= CELEX:31989L0391:EN:HTML.

[6] HSE, Working Together. Guidance on Health and Safety for Contractors and Suppliers (INDG268(rev)). Available at http://www.powys.gov.uk/uploads/media/indg268 en.pdf. Health and Safety Executive, 2002.

[7] HSE, Use of Contractors, a Joint Responsibility. INDG 368. Available at http://www.hse.gov.uk/pubns/indg368.pdf. Health and Safety Executive, 2002.

[8] HSE, Passport Schemes for health, safety and the environment: a good practice guide (INDG381). Available at http://www.hse.gov.uk/pubns/indg381.pdf. Health and Safety Executive, 2003.

[9] P. James, et al., Regulating Supply Chains to Improve Health and Safety. Industrial Law Journal, 2007. 36(2): p. 163-187.

[10] F. Loos and J.L. Deaut, Rapport Fait Au Nom de la Commission D'Enquete sur la Surete des Installations Industrielles et des Centres de Recherche et sur la Proection de Personnes et de L'environnment en cas D'Accident Industriel Majeur. 2002, Assemblee Nationale: Paris.

[11] NHS, Working with Contractors, available at http://www.healthyworkinglives.com/advicelemployeeissues/working-with-contractors.aspx. 2011: Scottish Centre for Healthy Working Lives.

[12] VCA, All about VCA. http://www.vcadirect.com/vcacourselall-about-vcal. 2011.

[13] D. Walters, et al., The Role and Effectiveness of Safety Representatives in Influencing Workplace Health and Safety, HSE Research Report 363 2005: HSE Books.

[14] D. Walters and P. James, Understanding the role of supply chains in influencing health and safety at work (Report submitted to the IOSH Research Committee). 2009.

[15] D. Walters and P. James, What motivates employers to establish preventive management arrangements within supply chains? Safety Science, 2011. 49(7): p. 988-994.

[16] A.L.J. Zwanikken, et al. Improving chain management of contractor safety. in 4th International Conference Working on Safety. 2008. Crete, Greece

[17] G. Zwetsloot, A. Hale, and S. Zwanikken, Regulatory risk control through mandatory occupational safety and health (OSH) certification and testing regimes (CTRs). Safety Science, 2011. 49: p. 995-1006. 